\title{
Approach to Trichobezoar Cases in Children: Literature Review
}

\section{Çocuklarda Trikobezoar Vakalarına Yaklaşım: Literatüre Genel Bakış}

\section{Huseyin KILINCASLAN'1 Ibrahim AYDOGDU', Mehmet KUCUKKOC², Nurcan Keskin OSMANOGLU²,}

Dilek KARACANOGLU²

'Department of Pediatric Surgery, Bezmialem Vakif University Faculty of Medicine, Istanbul, Turkey

${ }^{2}$ Department of Pediatrics, Bezmialem Vakif University Faculty of Medicine, Istanbul, Turkey

\section{ABSTRACT}

Trichobezoar is a mass found trapped in the gastrointestinal system formed from the ingestion of hair. They are mostly localized inside the stomach, and they can occasionally extend from the pylorus into the duodenum and small intestines. At the same time, they are almost always associated with trichotillomania, trichophagia, and other psychiatric diseases. Trichobezoar can be easily confused with other diseases characterized by abdominal pain and vomiting. Removal of the mass with laparotomic, laparoscopic, and endoscopic interventions is an available treatment approach. Among them, the laparotomic approach is the most effective treatment modality. Herein, we present a case and reviewed the literature from a general outlook in order to emphasize current, updated approaches to the pediatric cases with trichobezoar.

Key Words: Trichobezoar, children, review

\section{ÖZET}

Trikobezoar, yutulan saç ve diğer kılların gastrointestinal sistemde birikerek oluşturduğu kitleye denir. Çoğunlukla midede yerleşirler, bazen de pilordan duodenuma ve ince barsaklara kadar uzanabilirler. Hemen hemen her zaman trikotillomani, trikofaji ve diğer psikiyatrik hastalıklarla beraberdirler. Trikobezoar diğer karın ağrısı ve kusma nedeni olan hastalıklarla kolayca karışabilir. Laparotomi, laparoskopi veya endoskopi ile kitlenin çıkarılması uygun tedavi yaklaşımlarıdır. Bunların içinden laparotomi halen en etkin tedavi şeklidir. Biz burada çocukluk çağındaki trikobezoar vakalarına güncel yaklaşımı vurgulamak amacıyla literatüre genel bir bakış yaptık.

Anahtar Sözcükler: Trikobezoar, çocuklar, derleme

\section{Giriş}

Trikobezoar, çoğunlukla proksimal gastrointestinal sistemi etkileyen, bulgu ve belirtileri nedeniyle diğer karın ağrısı ve kusmaya yol açan patolojilerle kolayca karışabilen nadir bir tablodur. İnsan saçı, yüzeyinin pürüzsüz olması ve keratinöz yapısı nedeniyle sindirime dirençlidir. Midenin mukoza katlantıları arasında kolayca birikir; zaman geçtikçe yiyecek parçaları ve mukus ile kitlesel bir hal alır, böylece trikobezoar oluşur (1-4). Trikobezoarlar bazen pilordan duodenuma, jejenuma hatta kolona kadar ilerler. Vaughan ve ark. (5-8) bu duruma Rapunzel sendromu adını vermişlerdir. Bu sendromda trikobezoarın kuyruk kısmının kopmasına bağlı ince barsakta tıkanıklıklar oluşabilir (3, 9). Bazen de oddi sfinkterine direkt etki ederek aralıklı safra yolu obstrüksiyonu nedeni olabilir (10). Erken dönemde trikobezoarı spesifik olmayan semptomları dolayısı ile tanımak zordur. Bu yüzden psikiyatrik rahatsızlığı olan genç kızlarda, saçını koparma ve yutma davranışları varsa trikobezoardan şüphelenilmelidir. Ayrıca trikobezoarın mental retardasyon, yabancı madde kullanımı, pika, depresyon gibi durumlara eşlik edebileceği unutulmamalıdır (3). Trikobezoarların tanısı, spesifik olmayan semptomları olması ve ayrıcı tanıda kolay akla getirilmemesi nedeniyle genellikle gecikir. Büyüyen kitle mide ve barsakta mukozal ülserasyona hatta perforasyona neden olabilir. Literatürde tanısı geciken trikobezoara bağlı protein enerji malnütrisyonu, tıkanma sarıllğı, pankreatit hatta ölüm bile bildirilmiştir (3, 11-14). Laparoskopik ve endoskopik yöntemlerin gelişmesi sonrası trikobezoar tedavisinde laparotominin yeri sorgulansa da halen altın standart olma özelliğini korumaktadır (3, 
15-20). Amacımız yeni bir olgu sunumu eşliğinde literatürü gözden geçirmek ve bu vakalara çocukluk çağında yaklaşımın nasıl olması gerektiğini vurgulamaktır. Bu amaçla çocuk yaş grubunda literatürde bulunan tüm trikobezoar hastalarının kayıtlarına "Pediatric trichobezoar", "Rapunzel syndrome in children" ve "trichobezoar in children" anahtar kelimeleri kullanılarak Pubmed taramasıyla ulaşıldı.

\section{Bulgular}

Toplam 129 hastanın raporları birleştirildi. Hastaların 123’ü (\%95) kız ve 6'sı erkekti. Tanı anındaki ortalama yaş 9,4 olarak hesaplandı (19 ay -18 yaş). Rapunzel sendromu 52 (\%40) hastada tespit edildi. En sık görülen semptomlar ve bulgular sırasıyla; karında kitle 115 (\%88), karın ağrısı 91 (\%70), bulantı-kusma 83 (\%63), kilo kaybı 51 (\%39), kabızlık veya ishal $42(\% 32)$ ve hamatemez $8(\% 6)$ hastada mevcuttu. Hastaların 55'ine (\%42) endoskopik çıkarma işlemi denendi. Bunların 3'ü dışında diğerlerinde kitlenin büyük olması, parçalanamaması ve/veya Rapunzel sendromunun mevcut olması dolayısı ile işlem başarısız oldu. Laparoskopik girişimin yapıldığı 16 (\%12) hastanın 13'ünde başarılı olundu. Tüm hastaların 114'ünde (\%87) laparotomi yapıldı ve \%100 başarı elde edildi. Toplam 21 (\%16) hastada trikobezoar komplikasyona yol açmışı. Bunlar perforasyon $(n=14)$, invajinasyon $(n=2)$, intestinal obstrüksiyon $(n=2)$, safra yolu obstrüksiyonu $(n=1)$, pankreatit $(\mathrm{n}=1)$ ve kolanjitti $(\mathrm{n}=1)$. Tablo 1'de literatürdeki tüm hastaların genel görünümü verilmiştir. Resim 1'de ise laparotomi ile trikobezoar kitlesi çıkardığımız kendi vakamıza ait görünümler verilmiştir.

\section{Tanı}

Trikotillomani (saç-kıl koparma) ve trikofaji (saç-kıl yeme) gibi alışkanlıkların eşlik ettiği psikiyatrik rahatsızlı̆̆ı olan hastalarda karın ağrısı, karında kitle ve kusma gibi şikayetler varsa trikobezoar da düşünülmelidir. Tanı koymada görüntüleme yöntemlerinin önemli yeri vardır. Direkt grafilerin ise özgüllüğü düşük olsa da kontrastlı grafiler ayırıcı tanıda daha yararlı olabilir. Kitlenin doğrudan görülebilmesi, kitlenin yapısı hakkında bilgi verebilmesi nedeniyle endoskopi yüksek duyarlılık ve özgüllüğe sahiptir (3).

\section{Klinik Değerlendirme ve Takip}

Trikobezoar, nadir görülmesine rağmen acil tablolara yol açabilen bir durumdur. Endoskopi ve laparoskopi gibi minimal invaziv girişimlerin devreye girmesi ile tedavisindeki seçenekler artmıştır (15-23). Peristaltizmle kolay hareket etmeyen ve yapıları nedeniyle de sindirime dirençli olan saç kıllarının yutulması ile trikobezoar oluşur. Trikobezoar sıklıkla genç kızlarda görülen bir durumdur. Bu oran $>\% 90$ olarak bildirilmiştir (9). En sık 13-20 yaş arasında gözlenir. En erken saptandığı yaş 19 ay olarak bildirilmiştir (13). Trikobezoarlar mide ameliyatları sonrası bir komplikasyon olarak da karşımıza çıkabilir. Gastrektomi veya vagotomi sonrası mide boşalımında güçlük, trikobezoar oluşumunu tetikleyebilir.

Belirti ve bulgular sinsi ve belirsiz olabilir. Bazen uzun süre asemptomatik seyredebilirler. Çocuklarda en sık bulgular epi-
Tablo 1. Literatürdeki pediatrik trikobezoar vakalarının genel özellikleri

\begin{tabular}{|c|c|}
\hline & Vaka sayısı \\
\hline Toplam & 129 \\
\hline $\mathrm{KIz}$ & $123(\% 95)$ \\
\hline Erkek & $6(\% 5)$ \\
\hline Rapunzel Sendromu & $52(\% 40)$ \\
\hline \multicolumn{2}{|l|}{ Semptom ve bulgular } \\
\hline Karında kitle & $114(\% 88)$ \\
\hline Karın ağrısı & $90(\% 69)$ \\
\hline Bulanti-kusma & $83(\% 63)$ \\
\hline Kilo kaybı & $50(\% 38)$ \\
\hline Kabızlık veya ishal & $42(\% 32)$ \\
\hline Hematemez & $8(\% 6)$ \\
\hline \multicolumn{2}{|l|}{ Tedavi şekli } \\
\hline \multicolumn{2}{|l|}{ Endoskopi } \\
\hline Toplam & $55(\% 42)$ \\
\hline Başarılı & $3(\% 2)$ \\
\hline \multicolumn{2}{|l|}{ Laparoskopi } \\
\hline Toplam & $16(\% 12)$ \\
\hline Başarılı & 13 \\
\hline \multicolumn{2}{|l|}{ Laparotomi } \\
\hline Toplam & $113(\% 87)$ \\
\hline Başarılı & 113 \\
\hline \multicolumn{2}{|l|}{ Komplikasyonlar } \\
\hline Perforasyon & 14 \\
\hline İnvajinasyon & 2 \\
\hline İntestinal obstrüksiyon & 2 \\
\hline Safra yolu obstrüksiyonu & 1 \\
\hline Pankreatit & 1 \\
\hline Kolanjit & 1 \\
\hline Rektal kanama & 1 \\
\hline
\end{tabular}

gastrik kitle (\%88), epigastrik ağrı (\%70), bulantı ve kusma (\%63), kilo kaybı (\%39), diyare veya konstipasyon (\%32) ve hematemezdir (\%6). Anemi ve hipoalbüminemi görülebilir. Çoğunlukla bu vakalarda spesifik olmayan semptomlar nedeniyle tanının geciktiği gözlenir. Tanının gecikmesi halinde trikobezoarlar ciddi komplikasyonlara yol açabilmektedir. En sık komplikasyon mide veya ince barsağın perforasyonudur. Çoğu vakada trikobezoarın oldukça büyük olması nedeniyle mide ve ince barsaklarda mukozanın kan dolaşımı azalır. $\mathrm{Bu}$ da ülserasyon veya perforasyonla sonuçlanmaktadır. İnvajinasyon, pankreatit, intestinal obstrüksiyon ve peritonit sık olmayan komplikasyonlardır $(3,24,25)$.

Trikobezoar epigastrik ağrı, kitle, yorgunluk ve kilo kaybı gibi spesifik olmayan semptomları olan özellikle ergen kızlarda ayırıcı tanıda düşünülmelidir. Psikiyatrik bir bozukluğun eşlik ettiği düşünülen durumlarda özellikle nüksün önlenmesi açısından psikiyatri konsültasyonu istenmelidir $(3,26)$. 


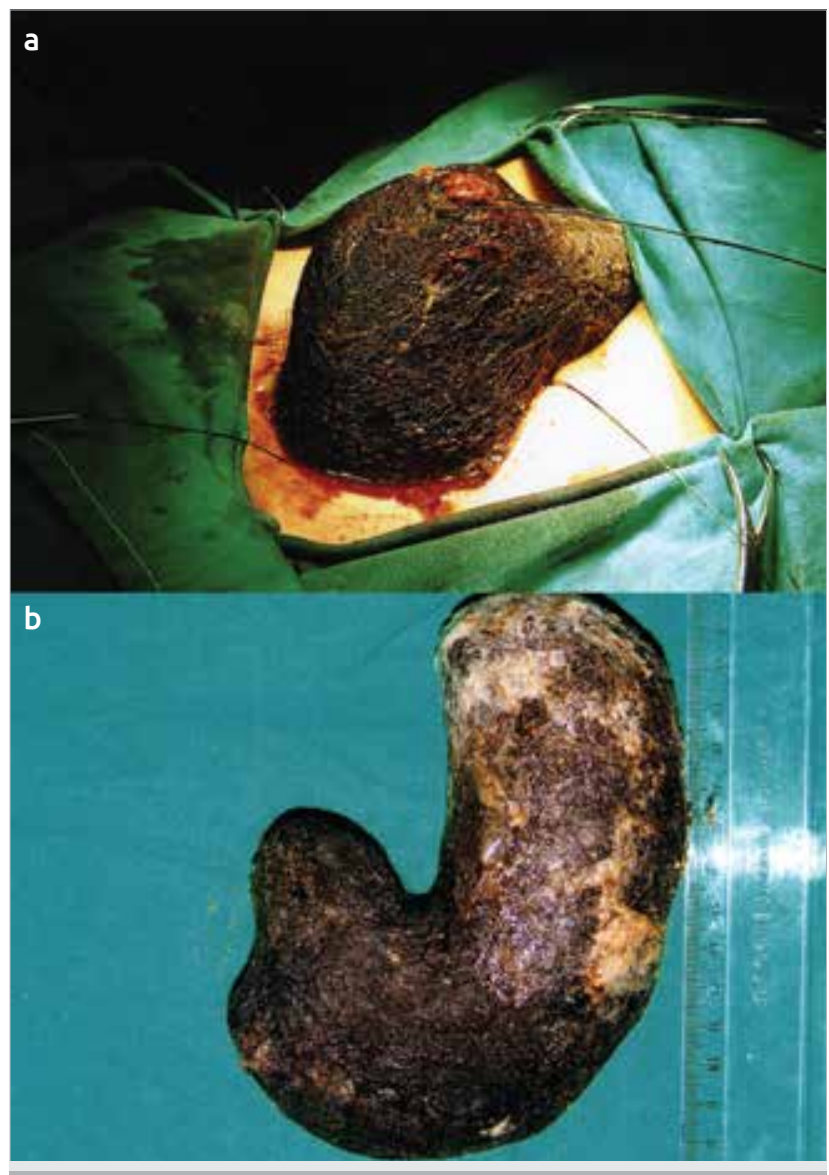

Resim 1. Operasyon esnasında ve sonrasındaki görümümler verilmiştir. Trikobezoarın karın dışına çıkarılışı görülmekte$\operatorname{dir}($ a). Mide şeklini almış dev trikobezoarın operasyon sonrası görünümü verilmiştir (b)

\section{Tedavi Yaklaşımları}

Tedavi seçenekleri arasında endoskopi, laparoskopi ve laparotomi yer alır. Trikobezoarın endoskopik olarak çıkarılması çok cazip olsa da bunu başarabilmek her zaman kolay değildir. Endoskopik olarak çıkarma ilk defa Saeed ve ark. (27) tarafından yapılmıştır. Çocuklarda trikobezoarın parçalanarak veya parçalanmadan endoskopik olarak çıkarılmasıyla ilgili başarısız girişimler oldukça fazladır $(21,28-30)$. Literatürde endoskopik olarak çıkarılması planlanan 55 çocuk vakasının sadece 3'ünde (\%2) başarılı olunmuştur (15, 16, 31). Deneyimler sonucunda endoskopinin trikobezoarın büyüklügü ve sertliği dolayısı ile etkin bir tedavi seçeneği olmadığı sonucuna varılmıştır. Endoskopi tanı açısından daha önemlidir. Parçalama ve çıkarma işlemleri sırasında endoskopla çok sayıda giriş-çıkış yapılması gerekir ki bu özofagus perforasyonuna neden olabilir. Endoskopik çıkarmanın diğer bir dezavantajı da parçalanan büyük parçaların piloru geçip distalde tıkanıklığa neden olabilmesidir $(29,32,33)$.

Laparoskopi ile trikobezoar çıkarılması ilk olarak Nirasawa ve ark. (18) tarafından rapor edilmiştir. Diğer bir çalışmada ise endoskopik ve laparoskopik yaklaşım birleştirilmiştir. Laparoskopi ile trikobezoar parçalanmış ve endoskopla çıkartılmış- tır (17). Laparoskopik yaklaşımın başarılı olduğu vakaların yanında (34-36) trikobezoarın ince barsaklara doğru uzanması dolayısı ile bu yöntem başarısız olduğu vakalar bildirilmiştir (3, 19, 20). Çalışmamızda toplam 129 vakanın 16'sında laparoskopik yaklaşımın denendiği ve bunların da 13'ünde başarılı olunduğu görülmüştür. Laparoskopik yaklaşımda ana parçadan kopan parçalar nedeniyle karşılaşılabilecek olası bir intestinal obstrüksiyona karşı dikkatli olunması gerekir. İşlem sırasında bezoar parçalarının intestinal sisteme dökülme ve bunun da gözden kaçma riski mevcuttur. Bu nedenlerle laparoskopinin etkinliği tartışmalıdır (37). Ayrıca laparoskopi portlarının giriş yerlerinin büyüklüğünün operasyonun ilerleyen safhasında trikobezoar parçalarının çıkarılabilmesi amacıyla 2-4 cm'e kadar genişletilmesinin gerektiğini belirten yayınlar da mevcuttur $(3,18,19)$.

Trikobezoarın çıkarılmasında halen altın standart laparotomidir $(38,39)$. Literatürdeki çocuk vakalarının 114'ünde (\%87) bu işlemin başarılı olduğu görülmüştür. Özellikle Rapunzel Sendromunda, laparotomiden daha iyi bir seçenek olmadığ belirtilmiştir (19, 40-42). Ayrıca ince barsaklara kadar uzanan trikobezoar vakaları bazı hastalıkları taklit edebilir. Bu gibi hastalarda laparotomi ile eksplorasyon yapılması yararlı olacaktır. Singh ve ark. (43) invajinasyonu taklit eden bir vakada laparotomi yapıp patolojinin trikobezoardan kaynaklandığını tespit etmişlerdir.

Trikobezoarın çıkarılması sırasında oluşan komplikasyonlar ise intestinal perforasyon, yara enfeksiyonu, pnömoni, paralitik ileus, trikobezoarın ileal anslara yer değiştirmesi ve fekal sizintidir $(3,24,44-49)$.

\section{Sonuç}

Trikobezoar, özellikle sıra dışı karın semptomları olan genç kızlarda akılda tutulması gereken bir tanıdır. Endoskopi, tanısal amaçlı ve gerekirse güvenli bir çıkarma işlemi için kullanılabilir. Literatürde endoskopi veya laparoskopinin tedavide üstünlügünü gösteren bir bulgu yoktur. Tedavide konvansiyonel laparotomi, özellikle de Rapunzel sendromunda altın standart olma özelliğini devam ettirmektedir. Ayrıca çoğunlukla trikotillomani, trikofaji ve diğer psikiyatrik hastalıklarla beraber olması nedeniyle cerrahi tedaviye ek olarak bu hastaların çocuk psikiyatristi tarafından takibe alınması nüksleri önleyecektir.

Peer-review: Externally peer-reviewed.

Author Contributions: Concept - H.K., I.A.; Design - H.K., M.K.; Supervision - H.K., I.A.; Funding - D.K., N.K.O.; Materials - H.K., I.A.; Data Collection and/or Processing - H.K., M.K.; Analysis and/or Interpretation H.K., I.A.; Literature Review - M.K., N.K.O.; Writing - H.K., I.A.; Critical Review - H.K., I.A.; Other - D.K., M.K.

Conflict of Interest: No conflict of interest was declared by the authors.

Financial Disclosure: The authors declared that this study has received no financial support. 
Hakem değerlendirmesi: Dış bağımsız.

Yazar Katkıları: Fikir - H.K., I.A.; Tasarım - H.K., M.K.; Denetleme - H.K., I.A.; Kaynaklar - D.K., N.K.O.; Malzemeler - H.K., I.A.; Veri toplanması ve/veya işlemesi - H.K., M.K.; Analiz ve/veya yorum - H.K., I.A.; Literatür taraması - M.K., N.K.O.; Yazıyı yazan - H.K., I.A.; Eleştirel İnceleme - H.K., I.A.; Diğer - D.K., M.K.

Çıkar Çatışması: Yazarlar çıkar çatışması bildirmemişlerdir.

Finansal Destek: Yazarlar bu çalışma için finansal destek almadıklarını beyan etmişlerdir.

\section{Kaynaklar}

1. Diefenbach GJ, Reitman D, Williamson DA. Trichotillomania: a challenge to research and practice. Clin Psychol Rev 2000; 20: 289309. [CrossRef]

2. Carr JR, Sholevar EH, Baron DA. Trichotillomania and trichobezoar: a clinical practice insight with report of illustrative case. J Am Osteopath Assoc 2006; 106: 647-52.

3. Gorter RR, Kneepkens CM, Mattens EC, Aronson DC, Heij HA. Management of trichobezoar: case report and literature review. Pediatr Surg Int 2010; 26: 457-63. [CrossRef]

4. Gonuguntla V, Joshi DD. Rapunzel syndrome: a comprehensive review of an unusual case of trichobezoar. Clin Med Res 2009; 7: 99-102. [CrossRef]

5. Vaughan ED Jr, Sawyers JL, Scott HW Jr. The Rapunzel syndrome. An unusual complication of intestinal bezoar. Surgery 1968; 63: 339-43.

6. Naik S, Gupta V, Rangole A, Chaudhary AK, Jain P, Sharma AK. Rapunzel syndrome reviewed and redefined. Dig Surg 2007; 24: 157-61. [CrossRef]

7. Crawley AJ, Guillerman RP. Rapunzel syndrome. Pediatr Radiol 2010; 40: S100. [CrossRef]

8. Bashir EA, Samiullah, Sadiq MA, Yusuf O, Karim K. Rapunzel syndrome. J Ayub Med Coll Abbottabad 2010; 22: 218-20.

9. Hoover K, Piotrowski J, Pierre K, Katz A, Goldstein AM. Simultaneous gastric and small intestinal trichobezoars-a hairy problem. J Pediatr Surg 2006; 41: 1495-97. [CrossRef]

10. Chogle A, Bonilla S, Browne M, Madonna MB, Parsons W, Donaldson J, et al. Rapunzel syndrome: a rare cause of biliary obstruction. J Pediatr Gastroenterol Nutr 2010; 51: 522-3. [CrossRef]

11. Ventura DE, Herbella FAM, Schettini ST, Delmonte C. Rapunzel syndrome with a fatal outcome in a neglected child. J Pediatr Surg 2005; 40: 1665-7. [CrossRef]

12. Mehta MH, Patel RV. Intussusception and intestinal perforations caused by multiple trichobezoars. J Pediatr Surg 1992; 27: 1234-5. [CrossRef]

13. Schreiber H, Filston HC. Obstructive jaundice due to gastric trichobezoar. J Pediatr Surg 1976; 11: 103-4. [CrossRef]

14. Shawis RN, Doig CM. Gastric trichobezoar with transient pancreatitis. Arch Dis Child 1984; 59: 994-5. [CrossRef]

15. Michail S, Nanagas V, Mezoff AG. An unusual cause of postfundoplication vomiting. J Pediatr Surg 2008; 43: 45-7. [CrossRef]

16. Wang YG, Seitz U, Li ZL, Soehendra N, Qiao XA. Endoscopic management of huge bezoars. Endoscopy 1998; 30: 371-4. [CrossRef]

17. Kanetaka K, Azuma T, Ito S, Matsuo S, Yamaguchi S, Shirono K, Kanematsu T. Two-channel method for retrieval of gastric trichobezoar: report of a case. J Pediatr Surg 2003; 38: 1-2. [CrossRef]

18. Nirasawa Y, Mori T, Ito Y, Tanak H, Seki N, Atomi Y. Laparoscopic removal of a large gastric trichobezoar. J Pediatr Surg 1998; 33: 663-5. [CrossRef]

19. Meyer-Rochow GY, Grunewald B. Laparoscopic removal of a gastric trichobezoar in a pregnant woman. Surg Laparosc Endosc Percutan Tech 2007; 17: 129-32. [CrossRef]
20. Hernández-Peredo-Rezk G, Escárcega-Fujigaki P, Campillo-Ojeda ZV, Sánchez-Martínez ME, Rodríguez-Santibá-ez MA, AngelAguilar AD, et al. Trichobezoar can be treated laparoscopically. J Laparoendoscop Adv Surg Tech A 2009; 19: 111-3. [CrossRef]

21. De Backer A, Van Nooten V, Vandenplas Y. Huge gastric trichobezoar in a 10 year old girl: case report with emphasis on endoscopy in diagnosis and therapy. J Pediatr Gastroenterol Nutr 1999; 28: 513-5. [CrossRef]

22. Al Wadan AH, Al Kaff H, Al Senabani J, Al Saadi AS. 'Rapunzel syndrome' trichobezoar in a 7-year-old girl: a case report. Cases J 2008; 1: 205. [CrossRef]

23. Kelly ME, Ferede A, Corbally M. Hairball-a case of mistaken identity. Ir Med J 2010; 103: 214-5.

24. Duncan ND, Aitken R, Venugopal S, West W, Carpenter R. The Rapunzel syndrome: report of a case and review of the literature. West Indian Med J 1994; 43: 63-5.

25. Jesus LE, Novelli RJM. Tricobezoares. Rev Col Bras Cir 2005; 32 : 157-9. [CrossRef]

26. Jensen AR, Trankiem CT, Lebovitch S, Grewal H. Gastric outlet obstruction secondary to a large trichobezoar. J Pediatr Surg 2005; 40: 1364-5. [CrossRef]

27. Saeed ZA, Ramirez FC, Hepps KS, Dixon WB. A method for the endoscopic retrieval of trichobezoars. Gastrointest Endosc 1993; 39: 698-700. [CrossRef]

28. Van Gossum A, Delhaye M, Cremer M. Failure of non surgical procedures to treat gastric trichobezoar Endoscopy 1989; 21: 113. [CrossRef]

29. Soehendra N. Endoscopic removal of a trichobezoar. Endoscopy 1989; 21: 201. [CrossRef]

30. Raikar S, Wali P, Khan S. Recurrence of Rapunzel syndrome. J Pediatr 2010; 157: 343. [CrossRef]

31. Aybar A, Safta AM. Endoscopic removal of a gastric trichobezoar in a pediatric patient. Gastrointest Endosc 2011; 74: 435-7. [CrossRef]

32. Hassani KI, El Bouhaddouti H, Benamar Y, Mazaz K, Taleb KA. [Gastric trichobezoar--about two cases]. Pan Afr Med J 2010; 6: 19.

33. Dumonceaux A, Michaud L, Bonnevalle M, Debeugny P, Gottrrand F, Turck D. Trichobezoars in children and adolescents. Arch Pediatr 1998; 5: 996-9. [CrossRef]

34. Cintolo J, Telem DA, Divino CM, Chin EH, Midulla P. Laparoscopic removal of a large gastric trichobezoar in a 4-year-old girl. JSLS 2009; 13: 608-11. [CrossRef]

35. Fraser JD, Leys CM, St Peter SD. Laparoscopic removal of a gastric trichobezoar in a pediatric patient. J Laparoendosc Adv Surg Tech A 2009; 19: 835-7. [CrossRef]

36. Tudor EC, Clark MC. Laparoscopic-assisted removal of gastric trichobezoar; a novel technique to reduce operative complications and time. J Pediatr Surg 2013; 48: 13-5. [CrossRef]

37. Yau KK, Siu WT, Law BK, Cheung HY, Ha JP, Li MK. Laparoscopic approach compared with conventional open approach for bezoar induced small bowel obstruction. Arch Surg 2005; 140: 972-5. [CrossRef]

38. Jain M, Solanki SL, Bhatnagar A, Jain PK. An unusual case report of rapunzel syndrome trichobezoar in a 3-year-old boy. Int J Trichology 2011; 3: 102-4. [CrossRef]

39. Sciarretta JD, Bond SJ. Gastric trichobezoar: abdominal mass in a child with sickle cell disease. Pediatr Emerg Care 2011; 27: 1014-5. [CrossRef]

40. Phavichitr N, Vathanasanti C. Rapunzel syndrome in a Thai girl with an asymptomatic abdominal mass: a case report. J Med Assoc Thai 2012; 95: 177-80.

41. Hilton AE, Hopper N, England S, Surtees P. Hair today. Arch Dis Child 2012; 97: 984. [CrossRef]

42. Fallon SC, Slater BJ, Larimer EL, Brandt ML, Lopez ME. The surgical management of Rapunzel syndrome: a case series and literature review. J Pediatr Surg 2013; 48: 830-4. [CrossRef]

43. Singh S, Wakhlu A, Pandey A, Gupta A, Ahmed I, Chandra N. Complicated Rapunzel syndrome mimicking intussusception. BMJ Case Rep 2011; 19; 2011. 
44. Varma A, Sudhindra BK. Trichobezoar with small bowel obstruction. Indian J Pediatr 1998; 65: 761-3. [CrossRef]

45. Sharma V, Sharma ID. Unusual presentation of trichobezoar. Indian Pediatr 1990; 27: 157-9.

46. Larsson LT, Nivenius K, Wettrell G. Trichobezoar in a child with concomitant coeliac disease: a case report. Acta Pediatr 2004; 93: 278-80. [CrossRef]
47. Memon SA, Mandhan P, Queshi JN, Shairani AJ. Recurrent Rapunzel syndrome: a case report. Med Sci Monit 2003; 19: 343-7.

48. Zent RM, Cothren CC, Moore EE. Gastric trichobezoar and Rapunzel syndrome. J Am Coll Surg 2004; 199: 990. [CrossRef]

49. Matejů E, Duchanová S, Kovac P, Moravanský N, Spitz DJ. Fatal case of Rapunzel syndrome in neglected child. Forensic Sci Int 2009; 10; 190: 5-7. [CrossRef] 